\begin{tabular}{|c|c|}
\hline Title & $\begin{array}{l}\text { Experimental and A nalytical Investigation of Crack Spacing and Width for Overlaid RC Beams at Elevated } \\
\text { Temperatures }\end{array}$ \\
\hline Author(s) & Zhang, Dawei; Rashid, Khuram; Wang, Bo; Ueda, Tamon \\
\hline Citation & $\begin{array}{l}\text { Journal of structural engineering, 143(12), } 4017168 \\
\text { https://doi.org/10.1061/A SCE)ST.1943-541X .0001910 }\end{array}$ \\
\hline Issue Date & 2017-12 \\
\hline Doc URL & http:/hdl.handle.net/2115/68165 \\
\hline Rights & $\begin{array}{l}\text { This material may be downloaded for personal use only. A ny other use requires prior permission of the A merican } \\
\text { Society of Civil Engineers. This material may be found at } \\
\text { https://ascelibrary.org/doi full/10.1061\% 28A SCE\% 29ST .1943-541X .0001910. }\end{array}$ \\
\hline Type & article (author version) \\
\hline File Information & ST 5473.pdf \\
\hline
\end{tabular}

Instructions for use 
ST5473

\title{
Experimental and Analytical Investigation of Crack Spacing and Width for Overlaid RC Beams at Elevated Temperatures
}

\author{
Dawei Zhang ${ }^{1}$, Khuram Rashid ${ }^{2}$, Bo Wang ${ }^{3}$ and Tamon Ueda ${ }^{4}$
}

\begin{abstract}
${ }^{1}$ Associate Professor, Department of Civil Engineering, College of Civil Engineering and Architecture, Zhejiang University, Hangzhou, China, 310058.Email: dwzhang@zju.edu.cn

${ }^{2}$ Assistant Professor, Department of Architectural Engineering and Design, University of Engineering and Technology, Lahore-54890, Pakistan (corresponding author). Email: khuram_ae@uet.edu.pk.

${ }^{3}$ School of Civil Engineering, Jilin Jianzhu University, Jilin, China. Email: bo_wang@126.com

${ }^{4}$ Professor, Division of Engineering and Policy for Sustainable Environment, Faculty of Engineering, Hokkaido University, Kita 13 Jo Nishi 8 Chome Kita-ku, Sapporo, Japan, 060-8628. Email: ueda@eng.hokudai.ac.jp
\end{abstract}

\section{Abstract}

Cracking in overlay-strengthened RC structures significantly influences their structural performance; however, the effect of elevated temperatures on cracking behavior remains unclear. This work summarizes the experimental and analytical investigations of flexural crack spacing and crack widths of overlaid reinforced concrete (RC) beams at elevated temperatures. Flexural crack spacing was observed experimentally by conducting four-point bending tests on control RC beams and beams overlaid by polymer cement mortar (PCM) together with steel reinforcements at 20,40 and $60{ }^{\circ} \mathrm{C}$ during both exposure and loading. The flexural crack width was measured during testing at 20 and $40{ }^{\circ} \mathrm{C}$. The flexural crack spacing and crack width increased with increasing temperature for the same reinforcement ratio in the overlay, while the flexural crack spacing and crack width decreased with increasing total area of steel reinforcements in the overlay at the same temperature. Based on the existing models for predicting the average crack spacing of overlaid beams, the bond deterioration of concrete/steel and PCM/steel bonds was incorporated to predict the flexural crack spacing of overlaid beams at elevated temperatures. The flexural crack width at an elevated temperature was predicted by incorporating the flexural crack spacing and the tensile stress of tension reinforcements in both the substrate beam and overlay at the cracked section. Close 
agreement was obtained between the experimental and predicted values of the flexural crack spacing and width.

Keywords: Overlay strengthened beam; Polymer cement mortar; Elevated temperature; Flexural crack spacing; Crack width.

\section{INTRODUCTION}

Retrofitting and strengthening reinforced concrete structures is one of the most suitable and viable solutions for deteriorated structures. Several materials have been introduced in the construction industry for repairs; some of the most commonly used materials are polymer cement mortar (PCM), fiber reinforced polymer (FRP) and ultra-high strength fiber reinforced concrete (UFC) panels. PCM is a cementitious material with better adhesion strength and resistance to aggressive environments than ordinary mortar and concrete.

PCM overlays are used to strengthen structural elements such as bridges, slabs and columns. Overlaid reinforced concrete (RC) beams were investigated in various studies, and the efficiency of overlaying for increasing the flexural stiffness and strength of beams under normal temperature conditions $\left(\sim 20{ }^{\circ} \mathrm{C}\right)$ was verified (Rashid et al. 2016, Rashid et al. 2015a, Satoh and Kodama 2005, Zhang et al. 2012). In practice, many RC structures are exposed to large daily temperature fluctuations, with maximum temperatures reaching $60{ }^{\circ} \mathrm{C}$ in peak summer, especially in the Middle East and some parts of North America (Al-Jabri et al. 2005). It has been reported that high temperature degrades the mechanical properties of concrete, PCM and PCM-concrete bonds and thus may affect the overall behavior of PCM overlaid RC members (Rashid et al. 2015a, Rashid et al. 2014, 2015b, Rashid et al. 2015d). In this context, the structural performance of PCM overlaid structures should be investigated at elevated temperature, and the required performance level should be ensured over the intended service life.

Cracking in overlaid RC structures significantly influences structural performance, 
including tensile, bending and shear stiffness, energy absorption capacity, ductility and the corrosion resistance of the reinforcement. Moreover, when investigating premature debonding failure, the crack spacing of overlaid beams was found to play an important role in transferring shear stress along the overlay-concrete interface and the normal stress generated in the substrate concrete (Raoof and Hassanen 2000, Zhang et al. 2012). Therefore, it is necessary to predict the cracking behavior of overlaid RC beams. Different structural codes and researchers present models for predicting the crack spacing and width of RC members with single-layer or multilayered reinforcement ((CEB-FIP) 2010, (CEN) 2004, (JSCE) 2007, Ceroni and Pecce 2009). Zhang et al. (2011) concluded that the existing codes are incapable of predicting the crack spacing of overlaid RC beams, and they proposed a new model by considering the equilibrium and compatibility equations between two adjacent cracks and verified the model using a large database. However, the applicability of the proposed model for overlaid beams at elevated temperatures has not yet been investigated. Moreover, there is currently no design equation available for predicting the crack width of overlaid RC beams at both normal and elevated temperatures.

The main objective of this study is to develop analytical models for predicting the flexural crack spacing and crack width of overlaid RC beams at normal and elevated exposure and loading temperatures. A large number of RC beams were prepared and overlaid with PCM and steel reinforcement at the beam soffit. Various amounts of reinforcement were used in the overlay. Both strengthened and unstrengthened beams were exposed to a specified temperature and then loaded in a four-point bending test at 20,40 and $60{ }^{\circ} \mathrm{C}$. The flexural crack spacing and crack width were measured at each testing temperature, and analytical models were proposed for predicting the flexural crack spacing and width. 


\section{EXPERIMENTAL PROGRAM}

Table 1 summarizes the testing conditions and number of specimens used for evaluating the flexural crack spacing and crack width of the beams. The main parameters are the exposure and loading temperature $\left(20,40\right.$ and $\left.60{ }^{\circ} \mathrm{C}\right)$ and the number and diameter of steel reinforcement bars $(2 \varnothing 6,3 \emptyset 6,4 \emptyset 6$ and $2 \varnothing 10)$ in the overlay. One and two specimens were tested at each temperature level for the control (unstrengthened) beams and overlaid beams, respectively. In total, 27 beams were tested. The designation adopted for the specimens in Table 1 was as follows: “CB” represents a control beam specimen without overlaying, "T" stands for the exposure temperature, and the terms before "T" indicate the number and diameter of steel reinforcement bars used in the overlay. For example, specimen " $3 \emptyset 6-40$ ” is an overlaid beam with 3 tension reinforcements bars with $6 \mathrm{~mm}$ diameter, exposed and loaded at $40{ }^{\circ} \mathrm{C}$.

\section{Materials and Specimen Preparation}

Fig. 1 presents the geometry and reinforcement details of the tested specimens. The substrate beam had a cross section of 150 x $200 \mathrm{~mm}$. The total length of the specimen was $1,800 \mathrm{~mm}$, with a clear span of $1,380 \mathrm{~mm}$. The tension and compression reinforcements of the substrate beams were two deformed steel bars with a $10 \mathrm{~mm}$ diameter. Sufficient shear reinforcement was provided by $\phi 6 \mathrm{~mm}$ plain bars spaced at $75 \mathrm{~mm}$ all through the span, and $25 \mathrm{~mm}$ clear concrete cover was maintained along the four sides of the longitudinal reinforcement. Ready-mixed ordinary concrete with a target compressive strength of $30 \mathrm{MPa}$ was used for the substrate beam. After curing of the substrate RC beam, the PCM-concrete interface was roughened until coarse aggregates were exposed, and then the interface was carefully cleaned. Then, varying diameters and numbers of steel reinforcement bars with a constant length of $1250 \mathrm{~mm}$, as indicated in Fig. 1(b) and Table 1, were fixed to the soffit of the substrate beam as tension reinforcement; polymer cement mortar (PCM) with a constant 
thickness of $25 \mathrm{~mm}$, width of $200 \mathrm{~mm}$ and length of $1280 \mathrm{~mm}$ was sprayed onto the treated concrete surface. Several $\phi 6 \mathrm{~mm}$ plain bars spaced at $100 \mathrm{~mm}$ were used as transverse reinforcement in the overlay to enhance the transverse rigidity of the overlay reinforcement. The reinforcements in the overlay had the same properties as those used for the substrate beam. The properties of the steel are mentioned in Table 2 and constituents with corresponding ratio of PCM are listed in Table 3. One thermal gauge was inserted at the PCM-concrete interface at the middle span of the beam to measure the internal temperature. Cubes with dimensions of $150 \mathrm{~mm}$ and $100 \mathrm{~mm}$ were used for the concrete and PCM to evaluate the compressive and splitting tensile strength, respectively.

\section{Testing and Exposure Conditions}

All specimens, both cubes and beams, were cured for one month and then exposed to 20, 40 or $60{ }^{\circ} \mathrm{C}$ temperatures for 16 hours before testing. This exposure period was confirmed to be sufficient by the inserted thermal couples, which indicated that the PCM-concrete interface temperature was the same as the exposure temperature after approximately12 hours of exposure. The cubes were heated in an oven and then wrapped with insulation sheets before being transferred to the testing machine. The testing machine for cubes was equipped with heaters and insulation sheets to control the loading temperature to be equal to the exposure temperature. For the beams, as indicated in Fig. 1(a), the desired temperature and relative humidity of $60 \%$ was maintained by an environmental chamber that is capable of controlling moisture and temperature conditions. All of the beams were exposed to the specified exposure conditions and tested at the same temperature using a self-balanced loading system established inside the chamber.

The cubes were tested for compressive strength and splitting tensile strength. The averages of three specimens were used to evaluate the strength at each temperature. The details of the setup and the results of the tests are presented in another paper that focused on 
the PCM-concrete interface bond properties (Rashid et al. 2015d). All beams were tested in four-point bending with a constant shear span of $460 \mathrm{~mm}$. Before loading, the front side of all beams were whitewashed with gypsum, and a grid spaced at $50 \mathrm{~mm}$ was placed on the surface to monitor the crack length and spacing during loading. Crack development was marked at various loading level during testing at 20 and $40{ }^{\circ} \mathrm{C}$. At $60{ }^{\circ} \mathrm{C}$, the crack spacing was marked after loading and reducing the temperature to the control condition. The crack width was measured from the extreme tensile fiber of PCM and concrete during various loading level at 20 and $40{ }^{\circ} \mathrm{C}$ using a crack width measurement device with an accuracy of $0.02 \mathrm{~mm}$; the crack width was not measured during the tests at $60{ }^{\circ} \mathrm{C}$.

\section{EXPERIMENTAL RESULTS AND DISCUSSION}

\section{Effect of Overlaying}

Fig. 2 presents a typical crack pattern of the control (Fig.2(b)) and overlaid (Fig.2(c)) RC beams at a stabilized cracking condition. The crack distributions at the side and bottom were consistent. The cracks initiated at a higher load in the overlaid beams than in the control beams at all temperature levels, and the cracking load increased with increasing reinforcement area in the overlay, as indicated in Table 4. The average crack spacing within the constant moment zone of each beam at the stabilized cracking stage was then calculated. Fig. 3 summarizes the measured average crack spacing at different temperature conditions. Specimens 2Ø6-40 and 2ø6-60had larger crack spacing than those the corresponding control beams CB-40 and CB-60, while specimen $2 \varnothing 6-20$ had a slightly smaller crack spacing than

that of specimen CB-20. Decreasing crack spacing was observed with increasing total perimeter steel reinforcements in the overlay at all temperature levels. Zhang et al. (2011) observed a similar tendency for PCM overlaid beams tested at room temperature. Based on their study, the average crack spacing increased with increasing tensile strength and effective 
tensile area of concrete and PCM but decreased with increasing the total perimeter of the tension reinforcements in the overlay and the bond strength of the concrete/steel and PCM/steel interfaces.

Fig. 4 compares the maximum crack width of the control specimens and overlaid beams at each temperature; the crack widths were measured at the extreme tensile fiber of the concrete and PCM during testing. For both the control and overlaid beams, the maximum crack width of both concrete and PCM increased in proportion to the increase in load after the crack was formed; after yielding of the tension reinforcement in the overlay and substrate beam, the crack width increased significantly compared to the load increment. A larger crack width was observed in PCM compared to concrete because the crack initiated from the extreme tensile fiber of PCM and propagated towards the compression side of the beam with further load application (Fig. 5). At the same load level and testing temperature, the maximum crack width of the overlaid beams decreased with increasing reinforcement area in the overlay (Fig. 4).

\section{Effect of Temperature}

For control beams, average crack spacings of $120 \mathrm{~mm}, 115 \mathrm{~mm}$ and $112 \mathrm{~mm}$ were observed in the beams tested at $20{ }^{\circ} \mathrm{C}, 40{ }^{\circ} \mathrm{C}$ and $60{ }^{\circ} \mathrm{C}$, respectively. The effect of temperature on the crack spacing of the control specimens was not obvious. It is worth mentioning that this effect was observed in the specimens with uniform temperature condition. For the cases where a temperature gradient exists, thermal stresses may affect the crack spacing. The average cubic compressive strength and the split tensile strength of concrete (CC) at different temperatures are listed in Table 5. The temperature had a negligible effect on the concrete strength, which explains its marginal effect on the crack spacing of the control specimens.

As shown in Fig. 3, for beams with the same reinforcement ratio in the overlay, the 
average crack spacing increases with increasing temperature. Decreasing first crack load was also observed with increasing temperature (Table 4). The cubic compressive strength and split tensile strength of PCM were determined from the average results of the three specimens and are presented in Table 5. The degradation in the mechanical properties of the PCM and the bond between the PCM and steel with increasing temperature is considered to be responsible for the increased average flexural crack spacing.

Fig. 5 presents the maximum flexural crack width of the control beams and overlaid beams at 20 and $40{ }^{\circ} \mathrm{C}$. For both the control and overlaid beams, the crack widths in beams exposed to higher temperatures were wider. For the control beams loaded at $20{ }^{\circ} \mathrm{Cand}$ at the load level of $30 \mathrm{kN}$, a $0.12 \mathrm{~mm}$ wide crack of the substrate concrete was observed, while at $40{ }^{\circ} \mathrm{C}$ and the same load level, the observed crack width was $0.26 \mathrm{~mm}$. As indicated in Fig. 5(a), at $20{ }^{\circ} \mathrm{C}$, the crack widths were measured at a load level of $48 \mathrm{kN}$, and they were 0.61 $\mathrm{mm}$ and $0.82 \mathrm{~mm}$ in the concrete and overlay part, respectively. At a similar load level, the crack widths increased to 1.09 and $1.8 \mathrm{~mm}$ for the substrate and overlay, respectively, during testing at $40{ }^{\circ} \mathrm{C}$. Similarly, in beam $3 \emptyset 6$ (Fig. 5(b)), an increase in crack width was observed with increasing temperature. At a load level of $55 \mathrm{kN}$, the crack width increased from 0.28 to $0.50 \mathrm{~mm}$ in the substrate part and 0.47 to $1.30 \mathrm{~mm}$ in the overlay part as the temperature increased from $20{ }^{\circ} \mathrm{C}$ to $40{ }^{\circ} \mathrm{C}$, respectively. The increasing tendency of the crack width was approximately the same for beams of $4 \varnothing 6$ and 2Ø10, as shown in Fig. 5(c) \& (d).

The bond strengths between concrete-steel and PCM-steel are affected by temperature, and a significant reduction was observed in the bond strength at elevated temperatures (Bingöl and Gül 2009, Chiang and Tsai 2003, Chiang et al. 2000). Elevated temperatures decrease the interaction of the physical bonding of cementitious material with steel. More slippage was observed at a high temperature in previous studies, which may be due to a significant reduction in PCM mechanical properties (Rashid et al. 2015d). Various codes give 
the prediction formula for crack width as a function of flexural crack spacing ((CEN) 2004, (JSCE) 2007), which was considered to be the main reason for increasing crack width with increasing temperature. It should be noted that other factors also influence the crack width, e.g., concrete cover, slippage of steel bars and distance between steel bars.

\section{ANALYTICAL DISCUSSION OF CRACK SPACING}

\section{Prediction of Crack Spacing for Overlaid Beams at the Control Condition}

Zhang et al. (2011) proposed a model for calculating the flexural crack spacing of overlaid beams using simple force equilibrium conditions, in which the uniaxial tensile force is considered between two adjacent cracks, as shown in Fig. 6. At the stabilized crack stage, the average flexural crack spacing of the concrete and overlay part can be calculated using Eq. (1).

$$
\begin{aligned}
S_{R C} & =\frac{3 f_{c t}\left(A_{R C, t}+A_{O L, t} \frac{E_{O L}}{E_{c}}\right)}{\left(\sum O_{R C} \tau_{b m, c}+\sum O_{O L} \tau_{b m, O L}\right)} \\
S_{O L} & =\frac{3 f_{t, O L}\left(A_{R C, t} \frac{E_{c}}{E_{O L}}+A_{O L, t}\right)}{\left(\sum O_{R C} \tau_{b m, c}+\sum O_{O L} \tau_{b m, O L}\right)}
\end{aligned}
$$

where:

$S=$ flexural crack spacing, $R C=\mathrm{RC}$ beam part, $O L=$ overlay part $(\mathrm{PCM}), f_{c t}$ and $f_{t, O L}$ are the tensile strengths of concrete and PCM, respectively, $E=$ modulus of elasticity, $O=$ perimeter of the steel bars, $\tau_{b m}=$ maximum bond stress of the concrete/PCM reinforcement, and $A$ = the effective tensile area of the concrete and PCM.

$$
\begin{aligned}
& A_{R C, t . \max }=\frac{A_{s, R C} \cdot f_{y \cdot R C}}{f_{c t}} \\
& A_{O L, t . \max }=\frac{A_{s, O L} \cdot f_{y \cdot O L}}{f_{t, O L}}
\end{aligned}
$$


where:

$A_{R C, t . \max }$ and $A_{O L, t . m a x}$ are the maximum tensile areas of the concrete part and the overlay part, respectively, and $A_{s}$ and $f_{y}$ are the reinforcement area and the reinforcement yield strength of the concrete or PCM, respectively. The other notations were previously defined.

It is clear from Eq. (2) that the effective area of the concrete or overlay is highly dependent upon the tensile strength of the concrete and PCM, which can be calculated using Eq. (3) from the splitting tensile strength following the CEB-FIP model code ((CEB-FIP) 2010).

$$
f_{t}=0.9 f_{s t}
$$

The details for calculating the related parameters can be found in Zhang et al. (2011).

The average stabilized crack spacings in the concrete part and overlay part were calculated using Eq. (1a) and Eq. (1b), respectively. The final crack spacing was calculated using Eq. (4), in which $k_{1}$ is the strain gradient coefficient and can be calculated according to the Canadian Standards Association CSA-S474 ((CSA-S474) 2004).

$S_{c r, a n a}=k_{1} \cdot \min \left(S_{R C}, S_{O L}\right)$

The above equations do not consider the effect of the surface condition of the steel reinforcement. Eq. (1) was modified to incorporate the effect of either plain or deformed bars, denoted by $\beta$. For a plain bar, $\beta$ is 1.3 , and for a deformed bar, $\beta$ is 1.0 , as used in JSCE ((JSCE) 2007). The modified Eq. (1) is presented as shown in Eq. (5).

$$
\begin{gathered}
S_{R C}=\frac{3 f_{c t}\left(A_{R C, t}+A_{O L, t} \frac{E_{O L}}{E_{c}}\right)}{\left(\beta_{R C} \sum O_{R C} \tau_{b m, c}+\beta_{O L} \sum O_{O L} \tau_{b m, O L}\right)} \\
S_{O L}=\frac{3 f_{t, O L}\left(A_{R C, t} \frac{E_{C}}{E_{O L}}+A_{O L, t}\right)}{\left(\beta_{R C} \sum O_{R C} \tau_{b m, c}+\beta_{O L} \sum O_{O L} \tau_{b m, O L}\right)}
\end{gathered}
$$


The experimental average flexural crack (Exp) spacing was compared with the analytical (Ana) values using Eq. (5), as presented in Fig. 7. At the control condition, the calculated flexural crack spacing shows satisfactory agreement with the experimental observations.

\section{Prediction of Crack Spacing for Overlaid Beams at Elevated Temperatures}

Eq. (5) was used to calculate the flexural crack spacing at the control condition. The effect of temperature on the tensile strength of concrete and PCM is considered in Eq. (6), which was proposed by the authors in their previous works based on their experimental results (Rashid et al. 2014, 2015b, Rashid et al. 2015c).

$f_{\text {t.pcm }}=1.2 f_{\text {to.pcm }} \exp (-0.0095 T)$

$f_{t, \text { conc }}=1.07 f_{\text {to,conc }} \exp (-0.004 T)$

where:

$f_{\text {to }}=$ split tensile strength $(\mathrm{MPa})$ at the control condition and $T=$ temperature $\left(20{ }^{\circ} \mathrm{C}<T<\right.$ $\left.60{ }^{\circ} \mathrm{C}\right)$.

Eq. (4) and Eq. (5) were also used to predict the flexural crack spacing at elevated temperatures by incorporating the tensile strengths and effective areas at the specified temperatures. At elevated temperatures, the tensile strengths of PCM and concrete were obtained from Eq. (6a) and Eq. (6b), respectively. The analytical values (Ana) were compared with the experimental observations (Exp), and close agreement was observed, as shown in Fig. 8 (Table 4). The ratio of the analytical crack spacing to the experimental crack $\left(S_{c r, a n a} / S_{c r, e x p}\right)$ was also measured, and it was observed to have a mean of 1.034 with a standard deviation of 0.046 .

\section{Prediction of Crack Width for Overlaid Beams}

JSCE (2007) proposed a model for predicting the crack width of RC beams by 
incorporating flexural crack spacing, as presented in Eq. (7), where $w$ is the crack width at the tension face of the member (mm), $\sigma_{s}$ and $E_{s}$ are the stress at the cracked section and the elastic modulus of the reinforcement, respectively, and $S_{c r}$ is the average flexural crack spacing. The concrete cover, transverse reinforcement spacing, surface and geometry all affect the crack width and were incorporated in the flexural crack spacing calculated using the JSCE method ((JSCE) 2007).

$$
\begin{aligned}
& w=S_{c r, O L}\left(\frac{\sigma_{s}}{E_{s}}\right) \\
& w=S_{c r, R C}\left(\frac{\sigma_{s}}{E_{s}}\right)
\end{aligned}
$$

Eq. (7) neglects the tensile strain in concrete because it is small as well as the tension stiffening effect between cracks. Due to tension stiffening, some of the stress is incorporated into the concrete, decreasing the stress borne by the steel reinforcement. The modified stress in the steel can be obtained using Eq. (8), which was proposed by Noël and Soudki (2014) for FRP reinforcement and has been proven to be applicable for other types of reinforcement.

$$
\begin{aligned}
& \sigma_{s m}=\sigma_{s}-\frac{0.4 \sqrt{f_{c, \text { conc }}^{\prime}}\left(2 b d_{c}-A_{s}\right)}{A_{s}} \\
& \sigma_{s m}=\sigma_{s}-\frac{0.4 \sqrt{f_{c, P C M}^{\prime}}\left(2 b d_{c}-A_{s}\right)}{A_{s}}
\end{aligned}
$$

where $\sigma_{s m}$ is the mean stress in the reinforcement between two cracks, $\sigma_{s}$ is the stress in the reinforcement at a cracked section, $b$ is the width of the beam, $d_{c}$ is the concrete cover, and $A_{s}$ is the steel reinforcement area.

Eq. (7) and Eq. (8) were used to calculate the crack width of the control and overlaid beams at the extreme tensile fiber of the concrete and PCM, respectively, at varying temperatures. The crack spacing was calculated at all temperatures using Eq. (5). Fig. 9 
compares the experimental crack width and the predicted crack width, which was predicted using Eq. (7) and Eq. (8) for PCM and concrete, respectively. To verify Eq. (7), a comparison was made by summarizing all of the data, as presented in Fig. 9. Close agreement was obtained between the observed crack width and the calculated crack width. Most of the data lies close to the $\mathrm{X}=\mathrm{Y}$ line at 20 and $40{ }^{\circ} \mathrm{C}$ in both the PCM overlay and the concrete (Fig. 9(a) and (b)). However, overestimation by up to $0.05 \mathrm{~mm}$ was observed in all of these cases. The ratio of the analytical to experimental crack width was 1.152 with a standard deviation of 0.350 for PCM and was 1.165 with a standard deviation of 0.318 for concrete. Further improvement is needed for predicting the crack width by incorporating other parameters that may affect the crack width, such as the concrete cover and the modulus of the materials.

\section{CONCLUSIONS}

The present work investigated the influence of temperature on the serviceability of PCMoverlaid RC beams. The flexural crack spacing was measured in RC and overlaid RC beams that were exposed to temperatures of 20,40 and $60{ }^{\circ} \mathrm{C}$ and then loaded under four-point loading at the same temperatures; the crack width was measured during testing at 20 and $40{ }^{\circ} \mathrm{C}$ only. In total, 27 beams were tested for reliability and applicability. The selected temperature range covers the climatic conditions in most regions in the world that have abundant RC structures. From the experimental observations and analytical work, the following conclusions were obtained:

(1) The flexural crack spacing decreased with increasing reinforcement area in the overlay part and increased with increasing temperature for both strengthened and unstrengthened beams.

(2) The method for calculating the flexural crack spacing was proposed for overlaid beams at all temperatures and was verified with the experimental observations. 
Most of the calculated data lie within $\pm 10 \%$ of the experimental results.

(3) The cracks were initiated from the tensile face of the overlay and propagated towards the compression side of the beam. The PCM crack width was wider than the concrete crack width because the PCM overlay was at the tension face of the substrate RC beam. The crack width increased with increasing temperature.

(4) The crack width was predicted by incorporating the predicted flexural crack spacing at temperatures of 20 and $40{ }^{\circ} \mathrm{C}$. The predicted crack width was also verified by the observed crack width. Close agreement was observed between the experimental and analytical crack width at both temperatures.

A large amount of data was presented in this work and can be used by structural designers and researchers for further investigations and to produce guidelines for repairing RC structures in specific regions.

\section{ACKNOWLEDGMENTS}

The financial support from the National Key Research and Development Program of China (2016YFC0701400), the Grant-in-Aid for Scientific Research (A) of the Japan Society of Promotion of Science (No. 26249064), the Natural Science Foundation of China (Grant No 51178206) and NEXCO Group Companies’ Support Fund to Disaster Prevention Measures on Expressways are greatly appreciated.

\section{References}

Al-Jabri, K. S., Hago, A., Al-Nuaimi, A., and Al-Saidy, A. (2005). "Concrete blocks for thermal insulation in hot climate." Cement and Concrete Research, 35(8), 1472-1479.

Bingöl, A. F., and Gül, R. (2009). "Residual bond strength between steel bars and concrete after elevated temperatures." Fire Safety Journal, 44(6), 854-859. 
Canadian Standard Associations (CSA). (2004). "S474 concrete structures.” CSA-S474, Mississauga, Ontario, Canada.

Ceroni, F., and Pecce, M. (2009). "Design provisions for crack spacing and width in RC elements externally bonded with FRP." Composites Part B: Engineering, 40(1), 17-28.

Chiang, C.-H., and Tsai, C.-L. (2003). "Time-temperature analysis of bond strength of a rebar after fire exposure." Cement and Concrete Research, 33(10), 1651-1654.

Chiang, C.-H., Tsai, C.-L., and Kan, Y.-C. (2000). "Acoustic inspection of bond strength of steel-reinforced mortar after exposure to elevated temperatures." Ultrasonics, 38(1), 534-536. Comité Euro-Internationale du Béton et Fédération Internationale e la Précontrainte (CEBFIP). (2010). “CEB-FIP model code.” Lausanne, Switzerland.

European Committee for Standardization (CEN). (2004). "Design of concrete structures, Part I: General rules and rules or buildings.” Eurocode 2, Paris.

Japan Society of Civil Engineers (JSCE). (2007). "Standard specification for concrete structures: Design.” JGC15, Tokyo, Japan.

Noël, M., and Soudki, K. (2014). "Estimation of the crack width and deformation of FRPreinforced concrete flexural members with and without transverse shear reinforcement." Engineering Structures, 59, 393-398.

Raoof, M., and Hassanen, M. (2000). "Peeling failure of reinforced concrete beams with fibre-reinforced plastic or steel plates glued to their soffits." Proceedings of the institution of civil engineers-structures and buildings, 140(3), 291-305.

Rashid, K., Zhang, D., Ueda, T., and Jin, W. (2016). "Investigation on concrete-PCM interface under elevated temperature: At material level and member level." Construction and Building Materials, 125, 465-478.

Rashid, K., Ueda, T., and Zhang, D. (2015a). “Study on strengthening of RC beam by overlaying with polymer cement mortar at elevated temperature.” Proc., Symposium on 
Reliability of Engineering System, Hangzhou, China.

Rashid, K., Ueda, T., Zhang, D., and Fujima, S. (2014). “Tensile strength and failure modes of concrete repaired by polymer cement mortar in hot region.” Proc., $6^{\text {th }}$ International Conference of Asian Concrete Federation, Seoul, Korea. pp. 1338-1345.

Rashid, K., Ueda, T., Zhang, D., and Fujima, S. (2015b). "Study on behavior of polymer cement mortar in severe environmental conditions."Proc., 37th Annual Convention of Japan Concrete Institute (JCI), Chiba, Japan. pp. 1597-1602.

Rashid, K., Ueda, T., Zhang, D., and Miyaguchi, K. (2015c). "Study on influence of temperature on bond integrity between polymer cement mortar and concrete." Proc., $5^{\text {th }}$ International Conference on Advances in Construction Materials, Whistler, Canada.

Rashid, K., Ueda, T., Zhang, D., Miyaguchi, K., and Nakai, H. (2015d). “Experimental and analytical investigations on the behavior of interface between concrete and polymer cement mortar under hygrothermal conditions.” Construction and Building Materials, 94: 414-425.

Satoh, K., and Kodama, K. (2005). "Central peeling failure behavior of polymer cement mortar retrofitting of reinforced concrete beams." Journal of materials in civil engineering, 17(2), 126-136.

Zhang, D., Ueda, T., and Furuuchi, H. (2011). "Average crack spacing of overlaystrengthened RC beams." Journal of Materials in Civil Engineering, 23(10), 1460-1472.

Zhang, D., Ueda, T., and Furuuchi, H. (2012). "Concrete cover separation failure of overlaystrengthened reinforced concrete beams." Construction and Building Materials, 26(1), 735745. 
Table 1. Summary of tests, number of specimens and testing conditions.

\begin{tabular}{|c|c|c|c|c|c|c|c|c|c|c|c|c|}
\hline \multirow[b]{3}{*}{ Beams } & \multirow[b]{3}{*}{$(n)_{O L}$} & \multirow{3}{*}{$\begin{array}{c}\mathrm{D} \\
(\mathrm{mm})\end{array}$} & \multirow{3}{*}{$\begin{array}{c}\text { Type of } \\
\text { rebar }\end{array}$} & \multirow{3}{*}{$\begin{array}{c}\text { Perimeter } \\
\text { (mm) }\end{array}$} & \multirow{3}{*}{$\begin{array}{l}\left(\mathrm{A}_{S}\right)_{O L} \\
(m m)^{2}\end{array}$} & \multicolumn{6}{|c|}{ Exposure and loading conditions } & \multirow[b]{3}{*}{ Abbreviation } \\
\hline & & & & & & \multicolumn{2}{|c|}{$20{ }^{\circ} \mathrm{C}$} & \multicolumn{2}{|c|}{$40{ }^{\circ} \mathrm{C}$} & \multicolumn{2}{|c|}{$60{ }^{\circ} \mathrm{C}$} & \\
\hline & & & & & & $S_{c r}$ & $w$ & $S_{c r}$ & $w$ & $S_{c r}$ & $w$ & \\
\hline \multirow[t]{2}{*}{ Control } & $\begin{array}{l}---- \\
\end{array}$ & ---- & Deform & $\begin{array}{ll}---- \\
\end{array}$ & ---- & 1 & 1 & 1 & 1 & 1 & $\begin{array}{ll}--- \\
\end{array}$ & CB-T \\
\hline & 2 & 6 & Plain & 37.70 & 56.10 & 2 & 2 & 2 & 2 & 2 & ---- & $2 \varnothing 6-\mathrm{T}$ \\
\hline Overlaid & 3 & 6 & Plain & 56.55 & 84.15 & 2 & 2 & 2 & 2 & 2 & ---- & $3 \emptyset 6-\mathrm{T}$ \\
\hline \multirow[t]{2}{*}{ beams } & 4 & 6 & Plain & 75.40 & 112.20 & 2 & 2 & 2 & 2 & 2 & ---- & $4 \varnothing 6-\mathrm{T}$ \\
\hline & 2 & 10 & Deform & 62.83 & 141.50 & 2 & 2 & 2 & 2 & 2 & ---- & $2 \emptyset 10-\mathrm{T}$ \\
\hline
\end{tabular}

$(n)_{O L}=$ Number of steel bars in overlay; $\mathrm{D}=$ diameter or steel bar; $\left(\mathrm{A}_{S}\right)_{O L}=$ Area of steel in overlay; $S_{c r}=$

Flexural crack spacing; $w$ = Crack width; $\mathrm{T}$ = loading temperature. 
Table 2. Properties of reinforcement.

\begin{tabular}{ccccc}
\hline Diameter $(\mathrm{mm})$ & $\begin{array}{c}\text { Yield strength } \\
\left(f_{y}\right)(\mathrm{MPa})\end{array}$ & $\begin{array}{c}\text { Ultimate } \\
\text { strength }\left(f_{u}\right) \\
(\mathrm{MPa})\end{array}$ & Elongation $(\%)$ & $\begin{array}{c}\text { Modulus of } \\
\text { Elasticity (GPa) }\end{array}$ \\
\hline 10 & 470 & 614 & 25 & 203 \\
6 & 430 & 617 & 35 & 200 \\
\hline
\end{tabular}


Table 3. Constituents with corresponding ratio of PCM.

\begin{tabular}{lc}
\hline Description & Details \\
\hline Unit volume mass & $2.90(\mathrm{~kg} / \mathrm{L})$ \\
Portland cement & $38.0(\%)$ \\
Silica sand & $62.0(\%)$ \\
Type of polymer & Copolymer of vinyl acetate \\
\end{tabular}


Table 4. Average crack initiation load, experimental and analytical crack spacing of beams at various temperature level.

\begin{tabular}{|c|c|c|c|c|c|c|c|c|c|}
\hline \multirow{3}{*}{$\begin{array}{l}\text { Overlaid } \\
\text { beam } \\
\text { specification }\end{array}$} & \multicolumn{3}{|c|}{ Crack initiation } & \multicolumn{3}{|c|}{ Experimental crack } & \multicolumn{3}{|c|}{ Analytical crack } \\
\hline & \multicolumn{3}{|c|}{ load $(\mathrm{kN})$} & \multicolumn{3}{|c|}{ spacing (mm) } & \multicolumn{3}{|c|}{ spacing (mm) } \\
\hline & $20^{\circ} \mathrm{C}$ & $40^{\circ} \mathrm{C}$ & $60^{\circ} \mathrm{C}$ & $20^{\circ} \mathrm{C}$ & $40^{\circ} \mathrm{C}$ & $60^{\circ} \mathrm{C}$ & $20^{\circ} \mathrm{C}$ & $40^{\circ} \mathrm{C}$ & $60^{\circ} \mathrm{C}$ \\
\hline $2 \varnothing 6$ & 19.5 & 17.5 & 13.5 & 115 & 134 & 123 & 126 & 137 & 132 \\
\hline $3 \varnothing 6$ & 24.5 & 20.0 & 17.5 & 92 & 104 & 115 & 99 & 111 & 108 \\
\hline $4 \varnothing 6$ & 26.5 & 22.0 & 19.0 & 84 & 88 & 90 & 82 & 93 & 92 \\
\hline $2 \varnothing 10$ & 29.0 & 22.0 & 21.0 & 96 & 104 & 100 & 96 & 107 & 105 \\
\hline
\end{tabular}


Table 5. Compressive and split tensile strength of materials at different temperature level.

\begin{tabular}{ccccc}
\hline \multirow{2}{*}{ Temperature $\left({ }^{\circ} \mathrm{C}\right)$} & \multicolumn{2}{c}{ Compressive strength $(\mathrm{MPa})$} & \multicolumn{2}{c}{ Splitting tensile strength (MPa) } \\
& CC & PCM & CC & PCM \\
\hline 20 & 28.29 & 59.69 & 3.53 & 6.06 \\
40 & 29.06 & 33.70 & 3.40 & 4.47 \\
60 & 31.43 & 27.70 & 3.39 & 4.21 \\
\hline
\end{tabular}

$\mathrm{CC}:$ Conventional concrete 


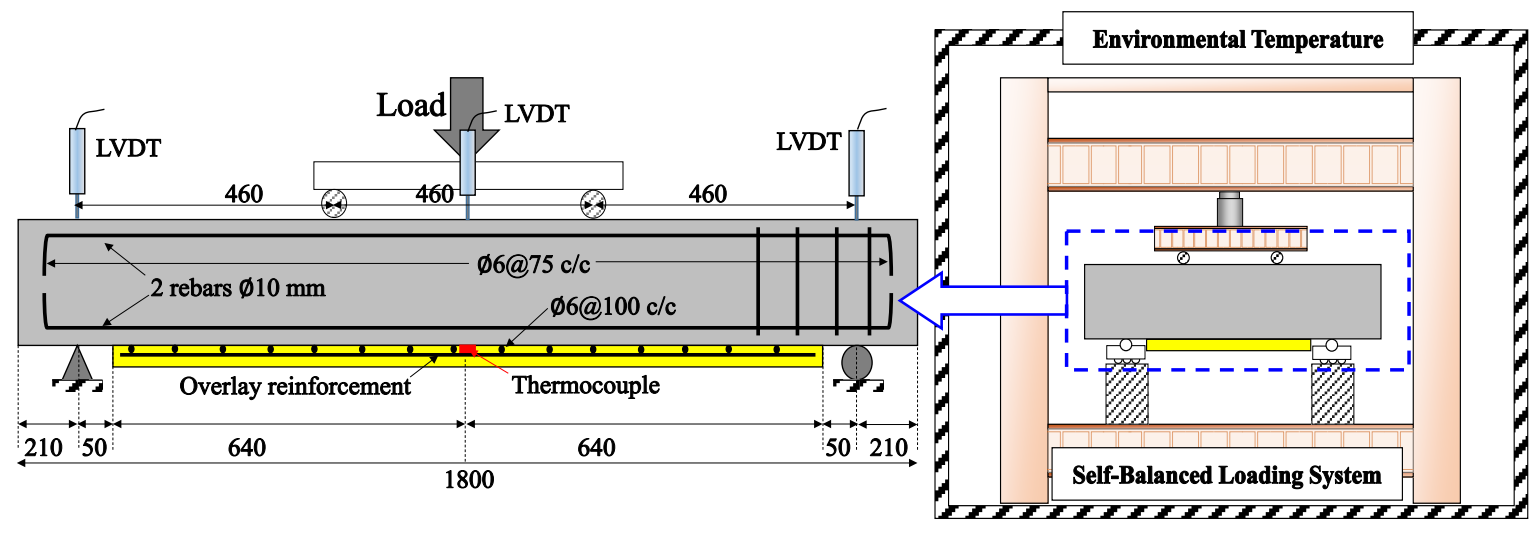

(a) Test setup of four-point loading test
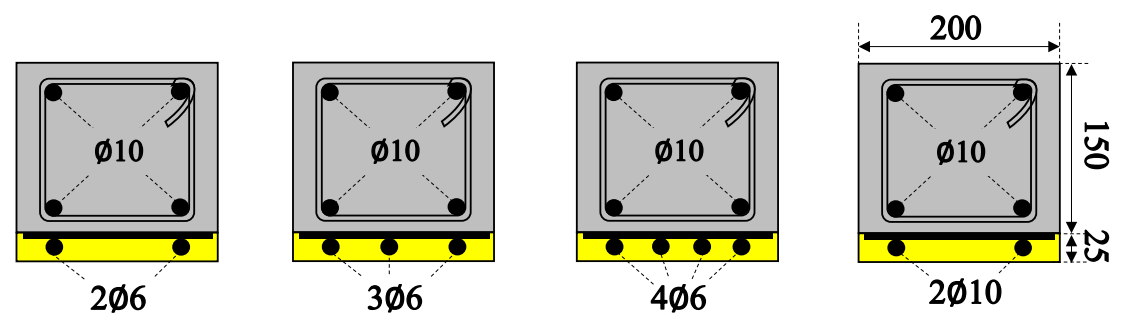

(b) Cross sectional area of strengthened beams with different reinforcement amount in overlay

Fig. 1. Longitudinal and cross sections of overlaid beams (unit : mm) 


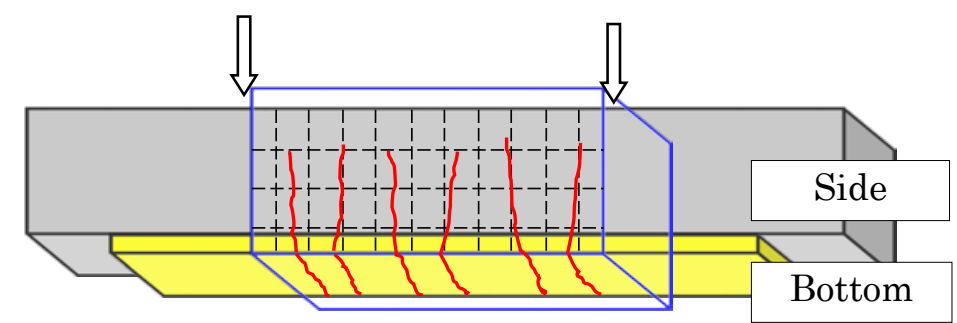

(a) Illustration of crack pattern in the constant moment zone

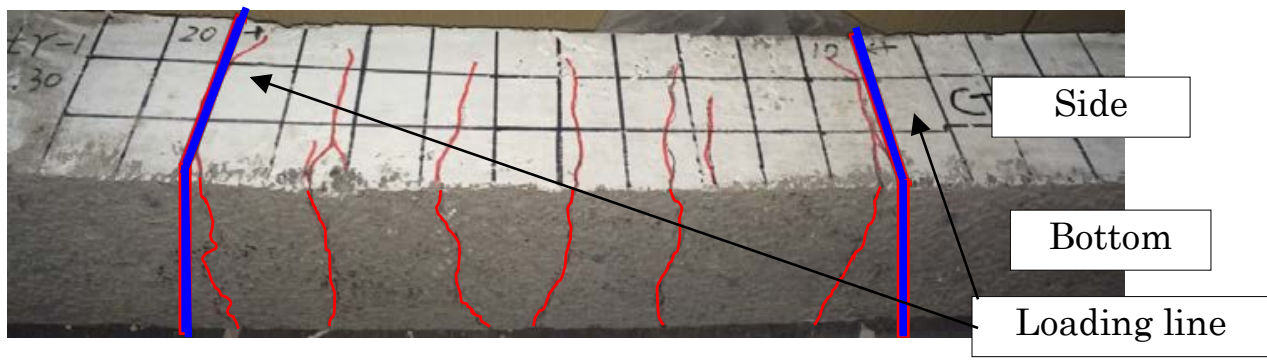

(b) Control beam

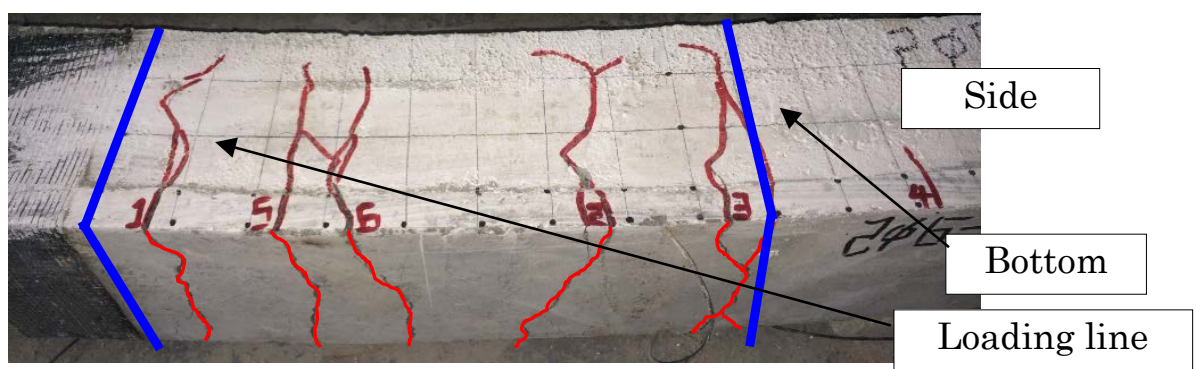

(c) Overlaid beam

Fig. 2. Typical crack pattern of tested beams in constant moment zone 


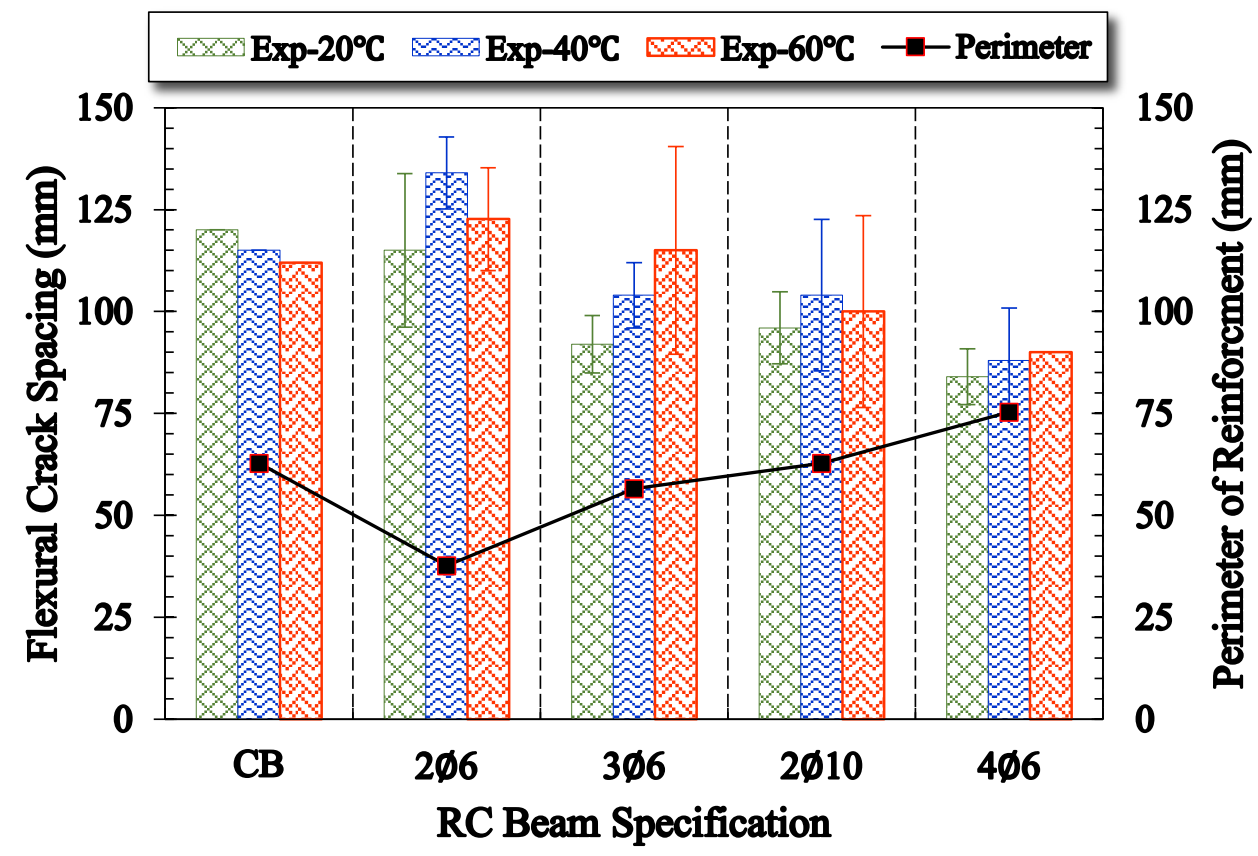

Fig. 3. Summary of flexural crack spacing of all types of beams. 


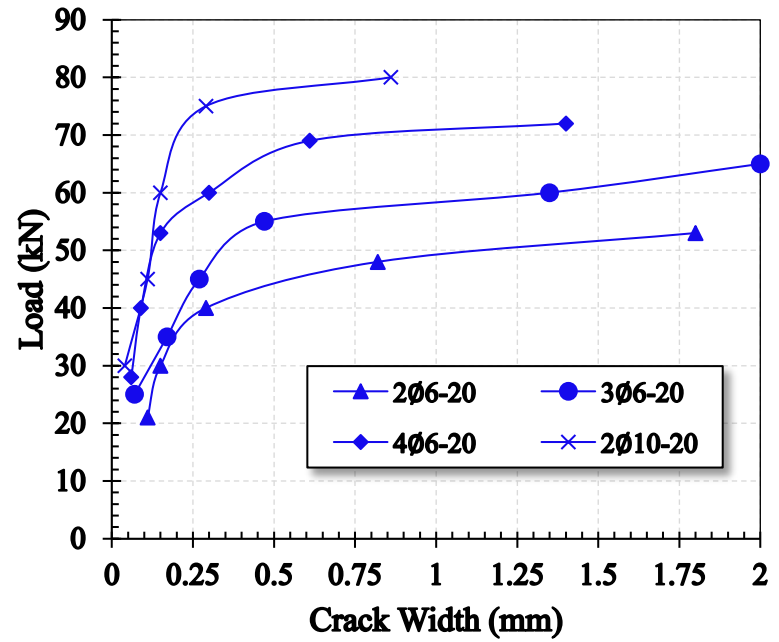

(a) $\mathrm{PCM}-20^{\circ} \mathrm{C}$

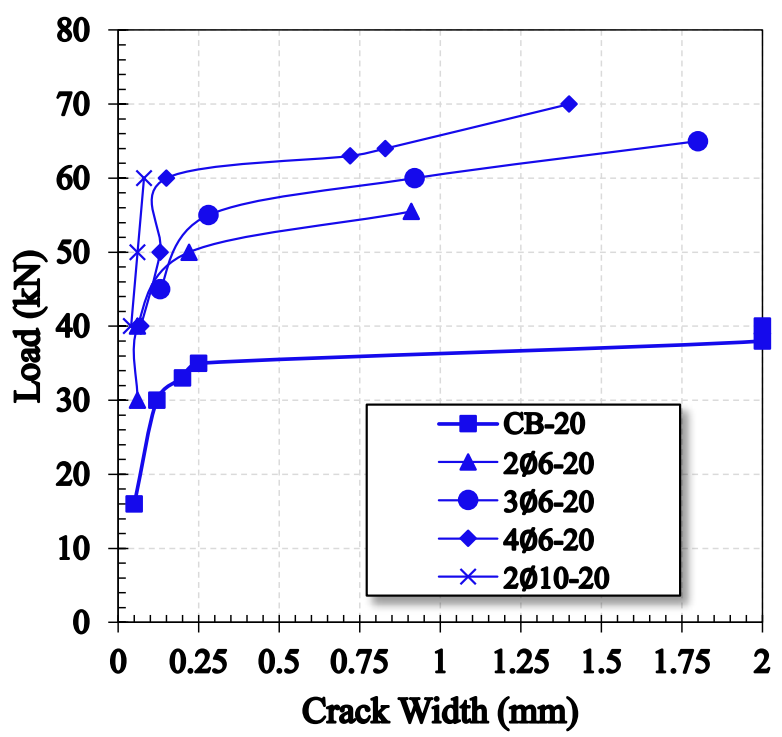

(c) Concrete- $20^{\circ} \mathrm{C}$

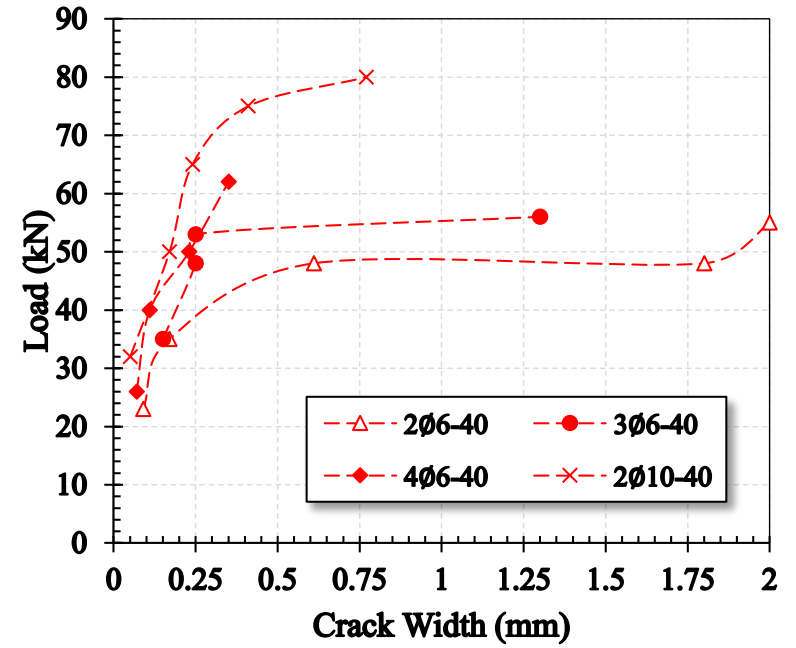

(b) $\mathrm{PCM}-40{ }^{\circ} \mathrm{C}$

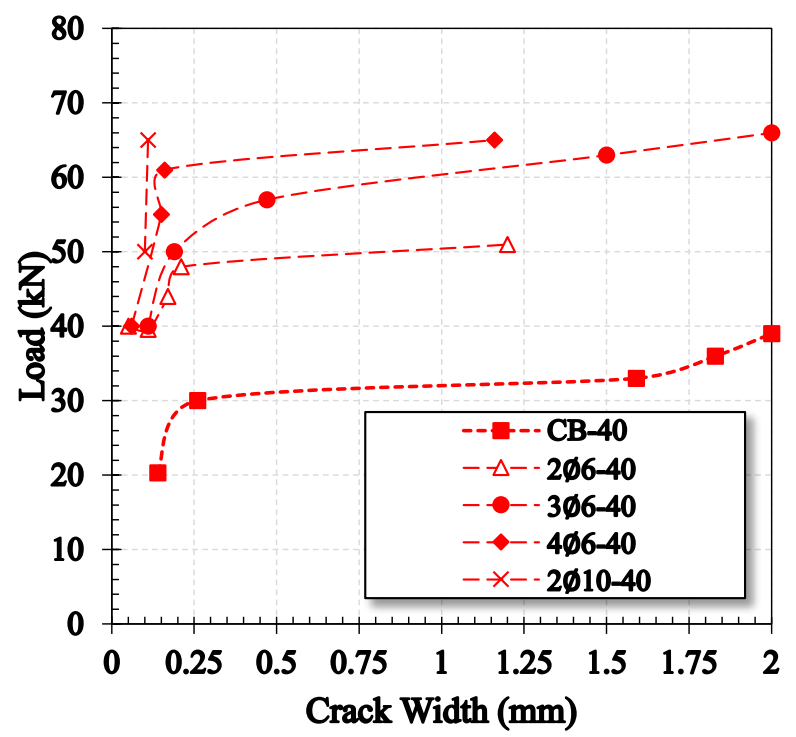

(d) Concrete- $40{ }^{\circ} \mathrm{C}$

Fig. 4. Summary of crack width of control and overlaid beams in PCM and concrete at each temperature level. 


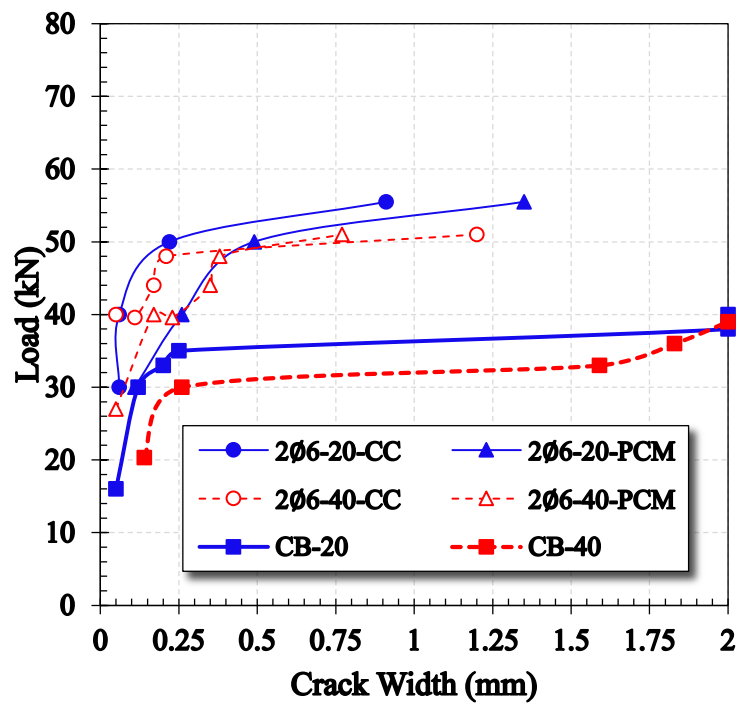

(a) CB and $2 \varnothing 6$ specimens

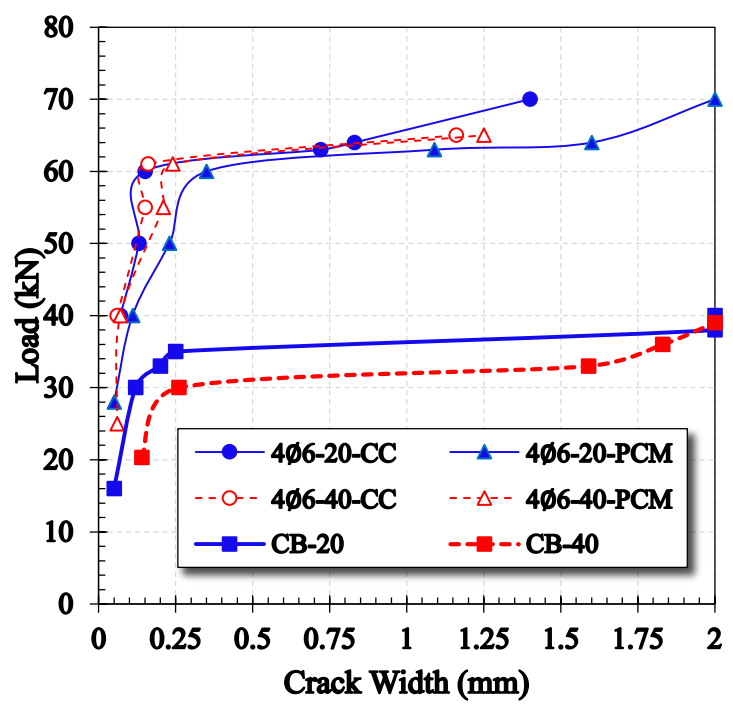

(c) CB and $4 \varnothing 6$ specimens

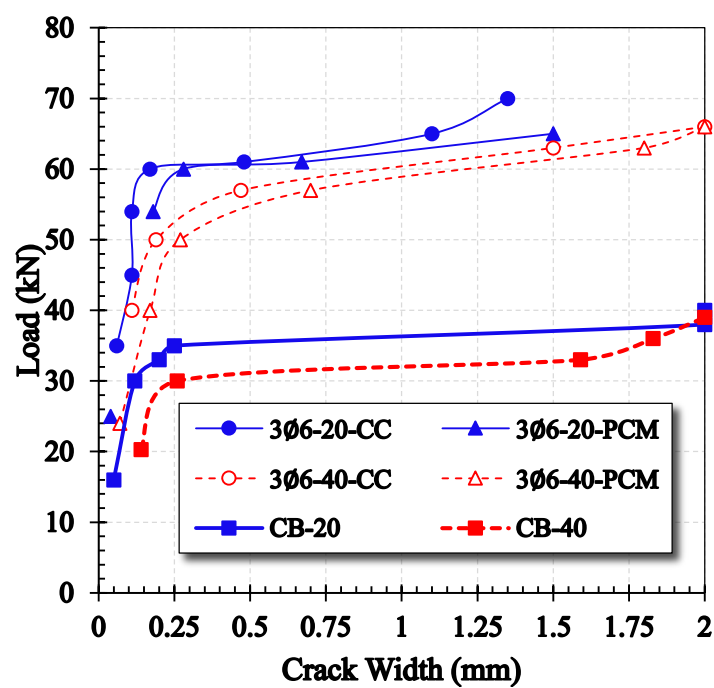

(b) $\mathrm{CB}$ and $3 \emptyset 6$ specimens

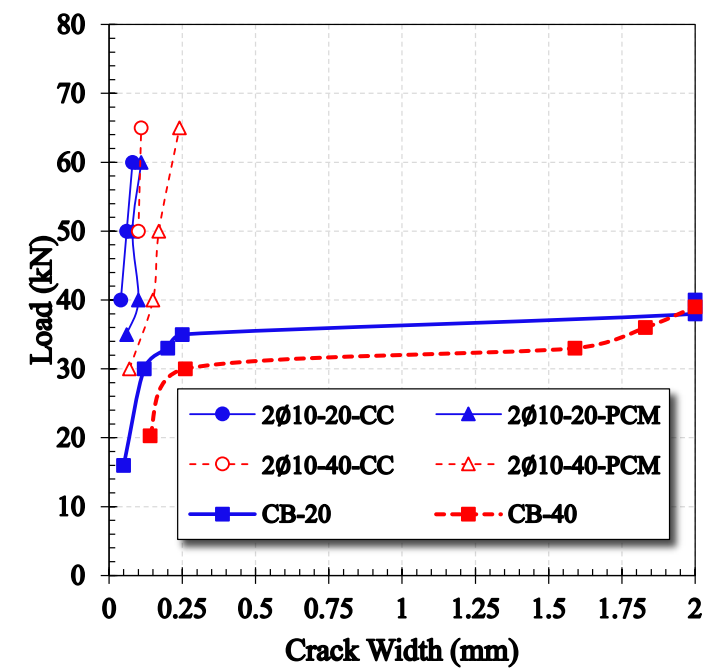

(d) CB and $2 \varnothing 10$ specimens

Fig. 5. Crack width of control and overlaid beams at 20 and $40{ }^{\circ} \mathrm{C}$. 


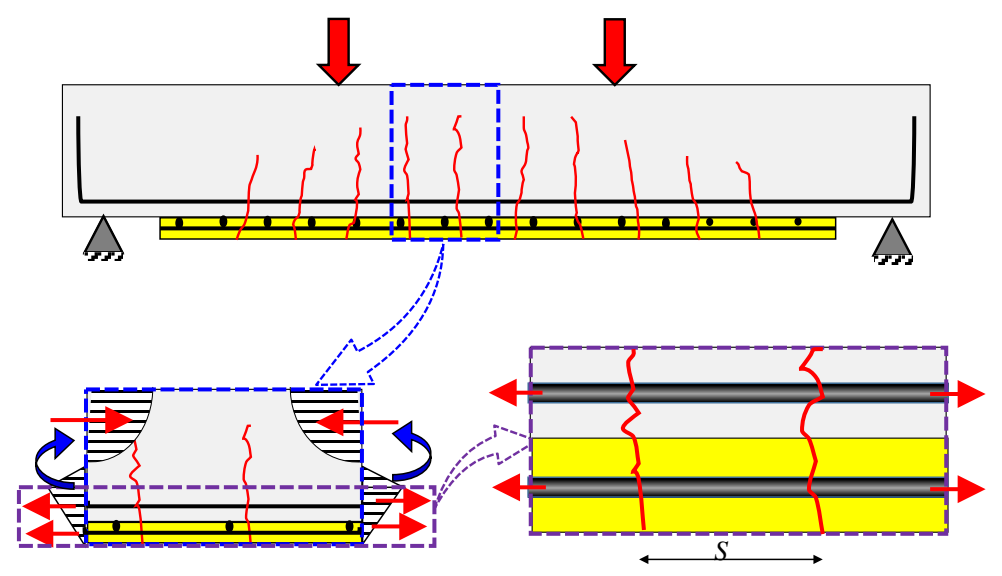

Fig. 6. Uniaxial tension between two adjacent cracks of overlaid beams. 


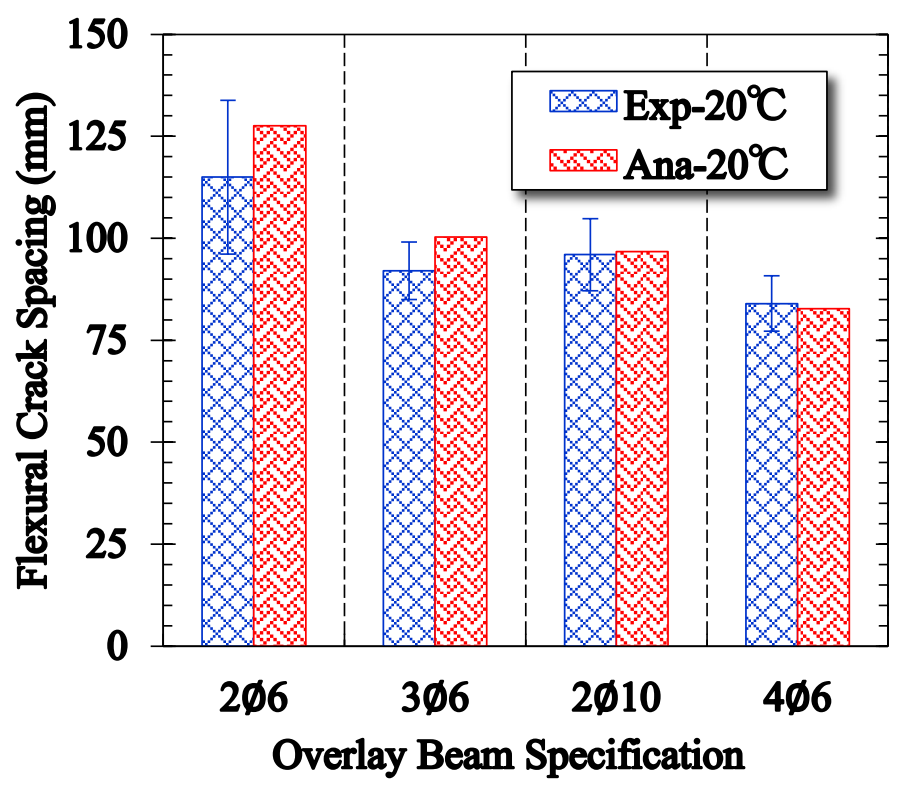

Fig. 7. Comparison of experimental crack spacing with predicted values at control condition. 


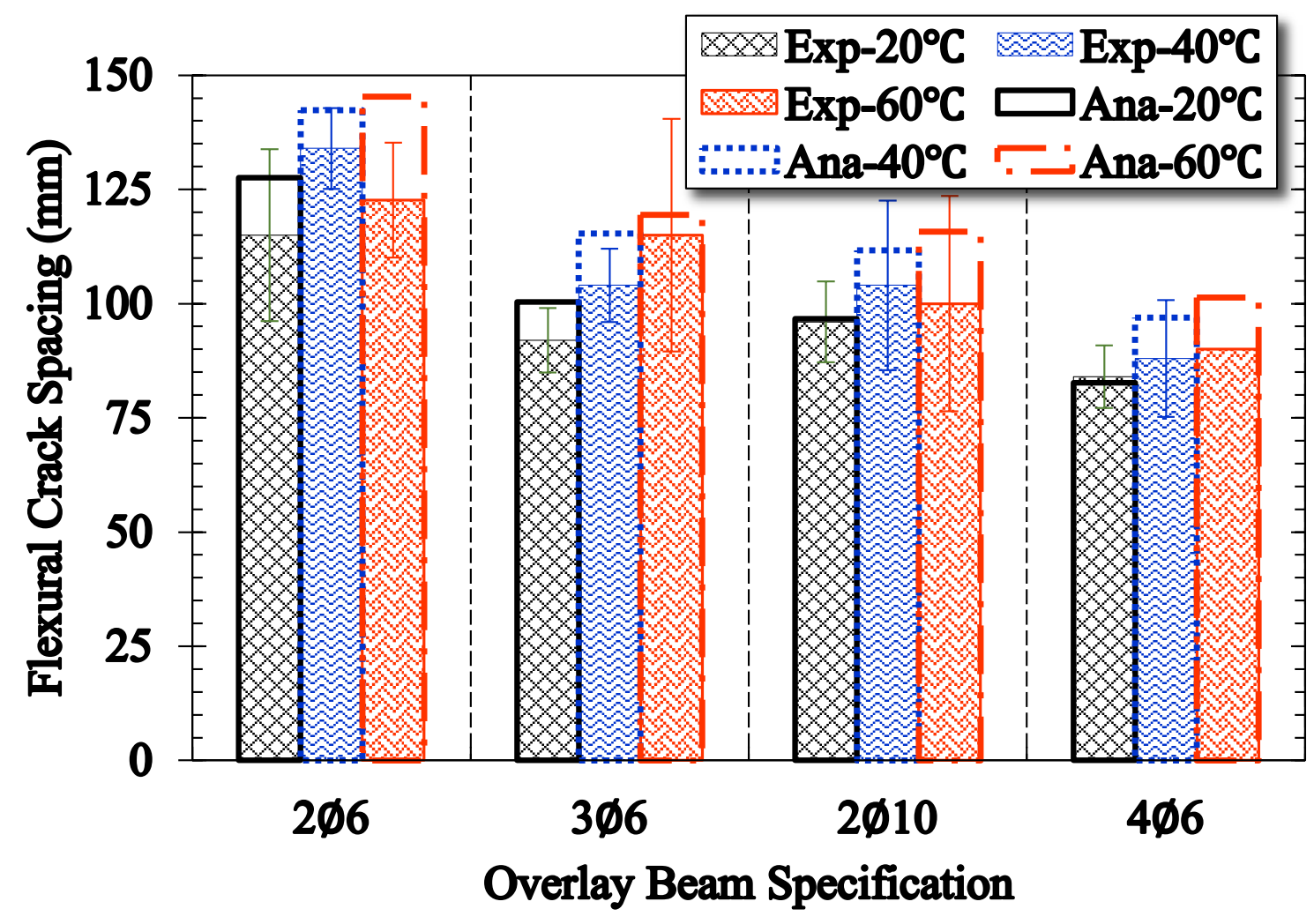

Fig. 8. Comparison of experimental crack spacing versus predicted values at different temperature levels. 


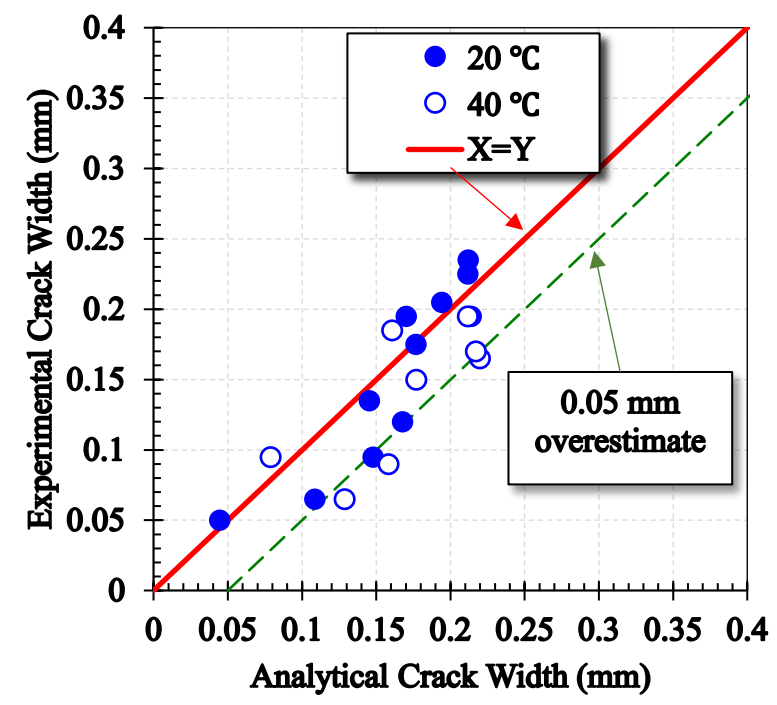

(a) PCM

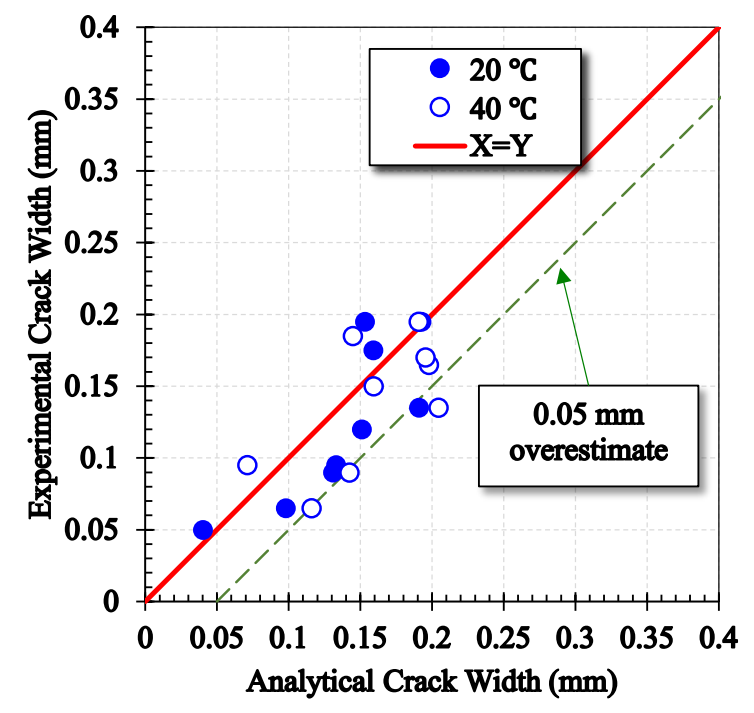

(b) Concrete

Fig. 9. Summary of crack width of all beams at both temperature levels. 